\title{
Aggregation of Zoospores of Phytophthora palmivora
}

\author{
By W. H. KO AND LYNNE L. CHASE \\ Department of Plant Pathology, University of Hawaii, Beaumont \\ Agricultural Research Center, Hilo, Hawaii 96720, U.S.A.
}

(Received 29 January 1973; revised 28 March 1973)

\begin{abstract}
SUMMAR Y
Zoospores of Phytophthora palmivora suspended in water aggregated within $2 \mathrm{~min}$ at $16{ }^{\circ} \mathrm{C}$. Individual spores in aggregates were separate and actively swimming. The optimum temperature for aggregation was $16{ }^{\circ} \mathrm{C}$. Aggregate formation depended on zoospore concentration and depth of suspension.
\end{abstract}

\section{INTRODUCTION}

Attraction of zoospores toward roots by root exudates is widespread in plant-pathogenic Phycomycetes (Hickman \& Ho, 1966). Such chemotaxis of zoospores is usually followed by hastened encystment and germination of spores settling on roots. During our studies on induction of indirect germination of Phytophthora palmivora sporangia in water at low temperature, we observed that zoospores released from sporangia often assembled themselves in groups without encysting. When these groups were dispersed by gentle shaking of the container, the zoospores aggregated again within a few min. Aggregation was considered to occur when zoospores suspended in water appeared to the naked eye as dense masses of spores when viewed against a dark background. We report herein this novel zoospore behaviour.

\section{METHODS}

Production of sporangia by Phytophthora palmivora was induced by growing the fungus on V-8 vegetable-juice agar under fluorescent light for 7 days at $24{ }^{\circ} \mathrm{C}$ (Aragaki \& Hine, 1963). A sporangium suspension was derived by spraying each culture plate with approximately $10 \mathrm{ml}$ of distilled water with an atomizer. Zoospores were liberated by incubating the sporangium suspension at $16^{\circ} \mathrm{C}$ for $\mathrm{I}$ to $2 \mathrm{~h}$, and were separated from sporangia by passing the suspension through a $20 \mu \mathrm{m}$ screen (Buckbee Mears Co.). Unless otherwise stated, $10 \mathrm{ml}$ of the resulting zoospore suspension was pipetted into a small Petri dish (6o $\mathrm{mm} \times \mathrm{I} 5 \mathrm{~mm}$ ) and kept at $16^{\circ} \mathrm{C}$ for observations of group formation. The zoospore concentration was determined according to Ko, Chase \& Kunimoto (1973) by first transferring Io $\mu \mathrm{l}$ of suspension with a microsyringe into $5 \mathrm{ml}$ of distilled water. After mixing, two drops ( $\mathrm{I} \mu \mathrm{l}$ each) of the diluted spore suspension were placed on a glass slide and the number of zoospores in each drop was counted under a microscope with a Io $\times$ objective.

\section{RESULTS}

Zoospores of Phytophthora palmivora aggregated within 2 min at $16{ }^{\circ} \mathrm{C}$. Grouping began with the formation of threadlike zoospore masses which soon segregated into umbrellashaped aggregates, each with a white centre (Fig. I). The zoospore aggregates dispersed when the plates were agitated gently, but as soon as the disturbance ceased zoospores 

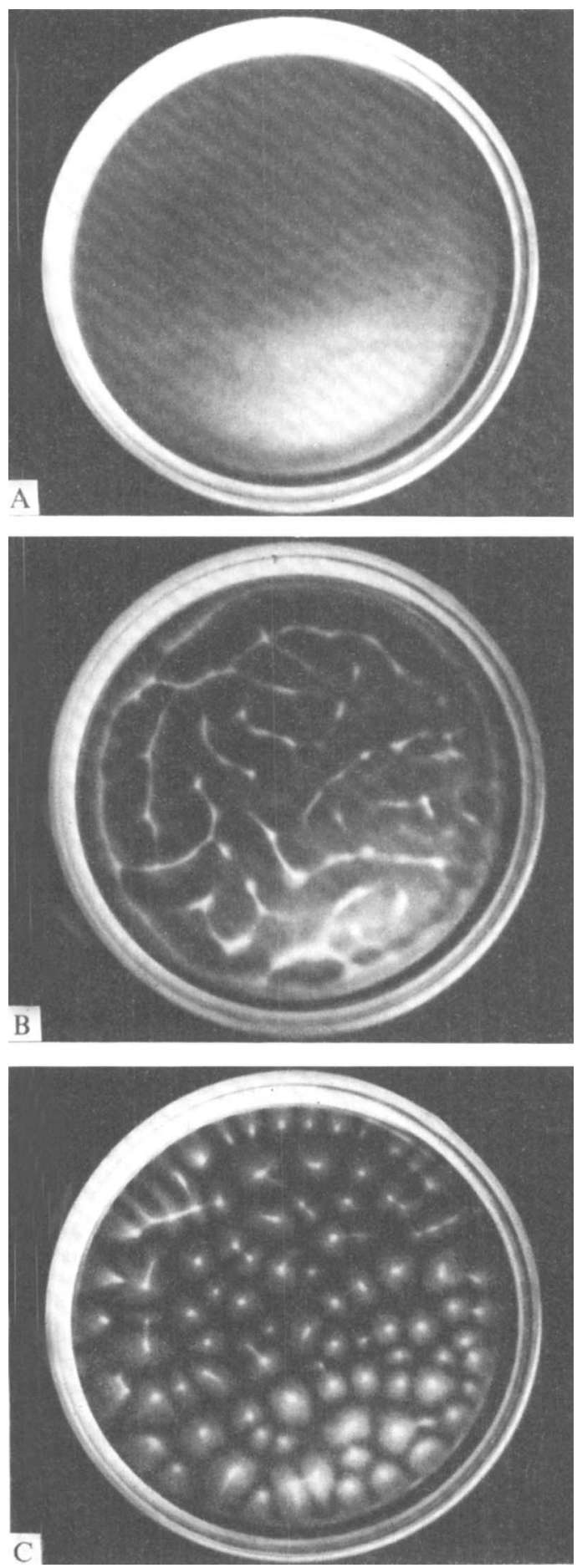

Fig. I. Group formation by Phytophthora palmivora zoospores at $16{ }^{\circ} \mathrm{C}$. (A) The beginning; (B) after $40 \mathrm{~s}$ (note the threadlike zoospore masses); (C) after $4 \mathrm{~min}$. Note a white centre in each aggregate and the formation of a 'bridge' during merger of aggregates. The concentration of zoospores was $35 \times 10^{5}$ spores $/ \mathrm{ml}$ suspension and the actual size of the Petri dish was $100 \mathrm{~mm} \times 15 \mathrm{~mm}$. 
Table I. Concentration of zoospores of Phytophthora palmivora within and between aggregates

Before aggregation, the zoospore concentration was about $20 \times 10^{5}$ zoospores $/ \mathrm{ml}$.

$\begin{array}{cccc}\begin{array}{c}\text { Experiment } \\ \text { (no.) }\end{array} & \begin{array}{c}\text { Aggregate } \\ \text { centre } \\ \left(\times 10^{-5}\right)\end{array} & \begin{array}{c}\text { Aggregate } \\ \text { periphery } \\ \left(\times 10^{-5}\right)\end{array} & \begin{array}{c}\text { Non- } \\ \text { aggregated } \\ \text { area }\left(\times 10^{-5}\right)\end{array} \\ \text { I } & 60 & 25 & 5 \\ 2 & 80 & 55 & 5 \\ 3 & 92 & 39 & 8 \\ 4 & 124 & 59 & 5\end{array}$

Table 2. Effect of initial concentration of Phytophthora palmivora zoospores on aggregation

\begin{tabular}{|c|}
\hline 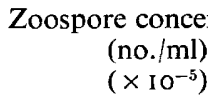 \\
\hline 25 \\
\hline 20 \\
\hline 15 \\
\hline IO \\
\hline $\begin{array}{l}5 \\
2 \cdot 5\end{array}$ \\
\hline
\end{tabular}

\begin{tabular}{|c|c|c|}
\hline \multicolumn{3}{|c|}{ No. of aggregates after } \\
\hline $2 \mathrm{~min}$ & $15 \mathrm{~min}$ & $30 \mathrm{~min}$ \\
\hline 36 & 31 & 23 \\
\hline 18 & I9 & 13 \\
\hline 9 & I I & I2 \\
\hline 2 & I 2 & 8 \\
\hline 0 & 0 & 0 \\
\hline 0 & 0 & 0 \\
\hline
\end{tabular}

started forming aggregates again. Aggregates close to each other tended to merge by the formation of a 'bridge' connecting the two aggregate centres. The concentration of zoospores in the centres and peripheries of the aggregates was, respectively, 12 to 25 times and 5 to 12 times higher than that in the non-aggregated area (Table I). The zoospore concentration between aggregates was about a third to a quarter of the concentration of the initial suspension. It appeared that the zoospores were being drawn toward the aggregate centre. When an aggregate was observed under the microscope with a $I 0 \times$ objective, most zoospores were seen swimming swiftly toward the centre and only a few were swimming more slowly in other directions. Non-aggregated zoospores were swimming randomly at an intermediate but similar velocity. Zoospores from four other isolates of $P$. palmivora also formed aggregates under these conditions.

Zoospore aggregation was temperature dependent. The optimum temperature was $16{ }^{\circ} \mathrm{C}$. No macroscopic aggregates were observed at $8,12,24$ and $28{ }^{\circ} \mathrm{C}$. Only a few aggregates formed at $20^{\circ} \mathrm{C}$. Zoospores dispersed when the Petri dish containing them was transferred from $16{ }^{\circ} \mathrm{C}$ to $24^{\circ} \mathrm{C}$. However, aggregates re-formed when it was transferred from $24{ }^{\circ} \mathrm{C}$ back to $16{ }^{\circ} \mathrm{C}$. Using a thermocouple with sensitivity of $\pm 0.14{ }^{\circ} \mathrm{C}$, we were not able to detect any temperature difference between the aggregate centres and the nonaggregated area.

The ability of zoospores to form macroscopic aggregates was correlated with the concentration of zoospores (Table 2). No aggregates formed at concentrations lower than $5 \times 10^{5}$ zoospores $/ \mathrm{ml}$. Table 3 shows that with the same amount of suspension and concentration of zoospores, aggregates formed in a smaller Petri dish, but not in a larger one. This indicated that aggregate formation also depended on depth of suspension.

Ability of zoospores to form aggregates depended on the concentration of only actively 
Table 3. Effect of Petri dish size on group formation of Phytophthora palmivora zoospores

The concentration of zoospores was about $35 \times 10^{5}$ zoospores $/ \mathrm{ml}$.

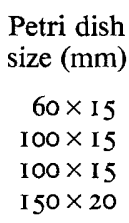

$\begin{array}{cc}\text { Amount (ml) } & \text { Depth (mm) } \\ \text { IO } & 5 \\ \text { I0 } & 2 \\ 25 & 3 \\ 25 & 2\end{array}$

\begin{tabular}{|c|c|c|}
\hline \multicolumn{3}{|c|}{ No. of aggregates after } \\
\hline $2 \mathrm{~min}$ & $15 \mathrm{~min}$ & $30 \mathrm{~min}$ \\
\hline 24 & $2 \mathrm{I}$ & 13 \\
\hline 0 & 0 & 0 \\
\hline 36 & 34 & 30 \\
\hline 0 & 0 & 0 \\
\hline
\end{tabular}

swimming zoospores, because addition of non-motile zoospores had no effect on zoospore aggregation. Zoospores began to encyst after prolonged incubation at $16^{\circ} \mathrm{C}$, and the ability of zoospores in a Petri dish to form aggregates decreased consequently. Usually, only a faint aggregate was left in each plate after $24 \mathrm{~h}$. These zoospores never formed aggregates again after they were dispersed by agitation, presumably because at this time the concentration of actively swimming zoospores was less than the minimum concentration needed for aggregation.

Light seemed to have no effect on aggregate formation. The number of aggregates formed in a Petri dish at $\mathrm{I} 6{ }^{\circ} \mathrm{C}$ under light or in darkness was about the same.

\section{DIS CUSSION}

The phenomenon of group formation of Phytophthora palmivora zoospores reported here is distinct from zoospore attraction toward plant roots. Attraction of zoospores toward roots by root exudates is usually followed by encystment and germination (Hickman \& Ho, I966), whereas, during group formation, individual zoospores of $P$. palmivora remained separate and were actively swimming.

The biological implication of such zoospore behaviour is not yet known. The number of zoospore aggregates formed in a dish was not affected by the presence of a young papaya root which is susceptible to the fungus (Ko, I97I), and zoospores in the aggregates were not attracted toward the root. It is therefore very unlikely that zoospore aggregation is involved directly in the host-parasite interaction.

Journal Series Paper no. 1529 of the Hawaii Agricultural Experiment Station. We thank Mr R. G. Chase for his assistance with the photographs.

\section{REFERENCES}

Aragaki, M. \& Hine, R. B. (1963). Effect of radiation on sporangial production of Phytophthora parasitica on artificial media and detached papaya fruit. Phytopathology 53, 854-856.

Hickman, C. J. \& Ho, H. H. (1966). Behaviour of zoospores in plant-pathogenic Phycomycetes. Annual Review of Phytopathology 4, 195-220.

Ko, W. H. (197I). Biological control of seedling root rot of papaya caused by Phytophthora palmivora. Phytopathology 6r, 780-782.

Ko, W. H., Chase, L. L. \& Kunimoto, R. K. (1973). A microsyringe method for determining concentration of fungal propagules. Phytopathology (in the press). 